\title{
Developing Young Learners' Local Culture Awareness and Global English: Integrated Instruction
}

\author{
Budsaba Kanoksilapatham
}

\begin{abstract}
This study highlights the positive impact of integrated instruction of local culture and global English. A school and a historical temple in Thailand were the premises of this study. To examine the impact of local culture instruction, a test was constructed and administered to a class of Grade 4 students in the first and last lessons of the five-week instruction. To assess the students' English ability, a tour guide simulation activity was organized upon completion of the instruction. Finally, to examine the students' attitude towards the integrated instruction, a mini-questionnaire was administered. The students had significantly higher gain scores regarding the knowledge of their local culture and were able to successfully perform the role of a tour guide at the monastery site. Finally, all students expressed their positive attitude towards the integrated instruction and activities employed. This study demonstrates a crucial step towards the national AEC integration in 2015.
\end{abstract}

Index Terms-English, Thailand, local culture, young learners.

\section{INTRODUCTION}

It has been agreed at the ASEAN Summit that the English language is positioned to become the working language of the ASEAN region. In response to this regional demand and to assure that the country of Thailand will smoothly undergo this transition, it is essential that Thai learners of English across the entire paradigm develop their English competence. However, English instruction in Thailand has met with limited success [1], [2]. A number of factors contributing to this unsatisfactory English performance include teaching methodologies and qualifications, materials and facilities, curriculum, learners' motivation, etc. Because of these prevailing weaknesses and limitations, a way to improve English education is crucially needed.

Elementary education is considered the grass roots, providing a foundation for other levels of the educational system, and thus deserves our utmost attention. As is the case, English textbooks and teaching materials used in elementary schools are commercial textbooks, catering to learners around the world. Typically, commercial textbooks published by a foreign press present western cultures, depicting unfamiliar settings which young Thai learners might not accumulate adequate background knowledge to grapple with the understanding of the textbooks. The students might not be motivated to study English because the content

Manuscript received April 15, 2014; revised June 15, 2014. This work was supported in part by the Faculty of Arts, Silpakorn University.

Budsaba Kanoksilapatham is with the English Department, Faculty of Arts, Silpakorn University, Nakhon Pathom, CO 73000 Thailand (e-mail: kanoksib@hotmail.com). presented in textbooks is not relevant to their actual lives. Therefore to help improve their English, their motivation to learn English needs to be enhanced.

The impact of commercial textbooks can be evident in the skill of reading. A national survey conducted by the National Statistical Office in 2011 [3] revealed that Thai learners in general did not spend much time reading. As a consequence, reading becomes a national issue of Thailand which needs strong cooperation from a number of sectors. In response to this phenomenon, the Office of the Basic Education Commission (OBEC), Ministry of Education, Thailand, initiated a number of national reading development plans in 2009, particularly with young learners [4].

This study represents an attempt to improve elementary school English education from the premise that local cultural knowledge and English lessons should be integrated for the maximum benefit of learning outcome. A school adjacent to a historical temple in a rural area of Thailand provides the ideal setting for, and impetus to, this research. The entire period of this instruction covered five consecutive weeks, including the first week of an orientation and a pre-test, followed by three weeks of instruction, concluded by one week of a post-test and tour guide simulation. First, the pre/post-test was constructed to measure the students' initial cultural knowledge and possible knowledge gain after three weeks of instruction. Next, instructional materials for the class were developed based on the historical accounts of the temple. Finally, tour guide simulation was conducted so that the students could demonstrate their English ability on the spot at a historical temple. Finally, a mini-questionnaire was administered to assess the students' attitude towards the lessons and activities pertaining to this project. The students' pre/post-test performance showed significant knowledge gain on the local culture. In a tour guide simulation activity at the temple, the students could successfully accomplish the task. The mini-questionnaire analysis indicated that the students enjoyed the lessons and activities. In short, this study demonstrates positive impacts of integrating local culture with English lessons. As a consequence, the students were motivated and became more aware of the importance of English as a means to empower them to be capable citizens in both the ASEAN regional and global contexts.

\section{METHODS}

This study has a general goal of fostering young Thai learners the value and awareness of local culture and improving their English competence. This general goal encompasses three specific objectives: 1) to estimate the students' significant gain in knowledge about local culture 
based on the comparison of their pre/post-test performance, 2) to assess their English knowledge related to their local culture based on their performance in a tour guide simulation activity, and 3) to examine the students' attitude towards all activities included in this integrated instruction. To accomplish each of the three objectives, the following procedures were performed.

\section{A. School and Local Cultural Site Description}

Wat Khok Kham School or the Khok Kham Temple School is a small size school situated in Samut Sakhon Province to the west of Bangkok. The school offers both pre-school and elementary school education. This school has only one class for each grade level (Grade levels 1 to 6). The class size is approximately 30 to 40 students. The parents of most of these students are laborers, working in nearby factories. Some of these students were born in Thailand, but are descendants of Burmese immigrants who came to work in Thailand. Because of the small size of the school, the budget received from the Ministry of Education is minimal and considered inadequate. Financial support from the parents is not available because of their low income. Fortunately, the headmaster of the school managed to mobilize funding from philanthropists in the area to purchase computers for the students to use in a computer room. To give you an idea what the classroom setting and students are like, see Fig. 1.

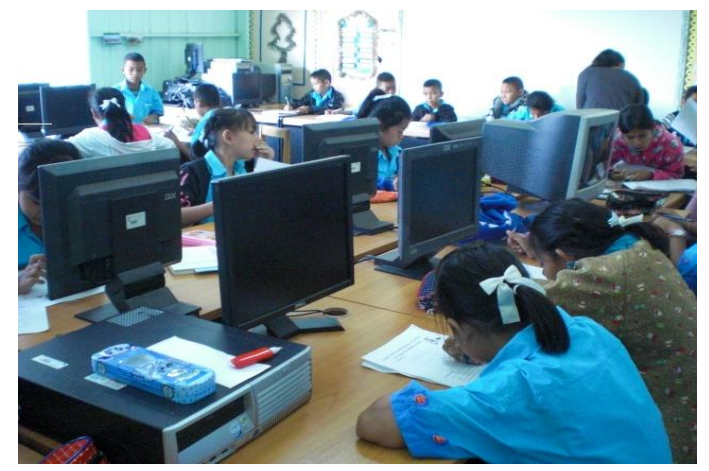

Fig. 1. Classroom setting and school students.

Adjacent to the school compound is a monastery precinct of a well-respected temple named Wat Khok Kham or the Khok Kham Temple. This temple is commonly known not only to the locals but to the entire country because of its historical background, the highly respected sacred Buddha image (Fig. 2), and its long history of more than 300 years. The abbot of the temple has occasionally provided financial support to the school, whereas the school staff has contributed as volunteers running temple-related activities.

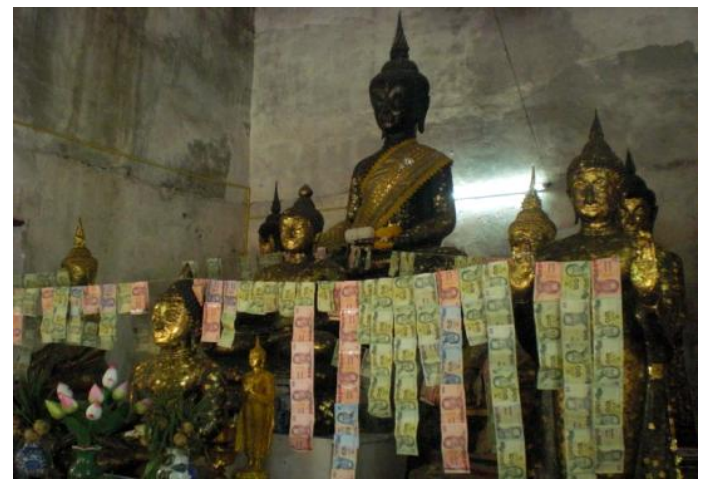

Fig. 2. Sacred Buddha image of the temple.
The size of the school and the fame of the temple as one of the historical grounds contribute to the ideal characteristics of being the site for implementing the integrated instruction of this study. First, the one class for each level of this school allowed the management and implementation of the integrated instruction for this research project to be possible. In addition, with the monastery precinct nearby, the integration of tour guide simulation contributes to the authentic, realistic, and practical nature of the language task.

Of all six levels (Grade levels 1 to 6), Grade 4 class was selected as a research target for a number of reasons. First, having been exposed to English instruction since Grade 1, the Grade 4 students of 10 or 11 years old should have adequate English knowledge to build on. Therefore, they would be somewhat ready to participate in academic activities designed and conducted in English for this project. In other words, with previous English exposure, the tasks and activities designed would not be too demanding or cognitively loading for them. In addition, these Grade 4 students were free from the preoccupation of the National Examination prescribed to Grade 6 students by the Ministry of Education. According to the Grade 4 roster, there were 38 students.

\section{B. Pre/Post-Test and Instructional Materials Development}

Given the fame and recognition of the Khok Kham temple, Samut Sakhon Province has published the historical accounts related to this temple in a +- and distributed to the general public. This two-page pamphlet contains important accounts of the temple in Thai, accompanied by colorful pictures of important items housed by the temple. Based on this two-page pamphlet in Thai, all instructional materials for this integrated instruction including the pre/post-test and three English lessons were developed and generated.

\section{Pre/Post-Test Development}

The purpose of the pre/post-test was to estimate the students' knowledge about local culture prior to instruction. To serve this purpose, the same pre/post-test was developed, consisting of a set of ten test items in the format of a completion task. The test was in Thai to validly measure their cultural knowledge. The questions asked include how old the temple was, when it was built, what is one of the most sacred items in the temple, etc. The answers required are words or phrases. The pre-test translated into English is presented in Appendix A.

\section{English Instructional Materials Development}

Based on the information contained in the pamphlet, three lessons in English were devised for this integrated instruction, forming the instructional materials of this study. Each lesson was allocated for one class meeting of two consecutive hours. The three lessons cover the topics of the history, location, and important Buddha image of the temple. The format of the three lessons is identical, consisting of two parts: vocabulary and reading. The creation of the instructional materials was meticulously carried out, taking into consideration the findings from previous research, in order to encourage the students' positive attitude towards the instruction.

First, vocabulary is regarded as one of the crucial and 
indispensable building blocks of language [5]-[8]. Also a number of scholars including [9]-[14] purport that vocabulary and reading comprehension are closely connected. Given the prominence and essence of vocabulary, every lesson begins with a set of ten vocabulary items related to the topic of the lesson.

Second, [15]-[20] congruently agree that L1 translation of a target word is quite beneficial because it enables students to understand the meaning simultaneously. Moreover, it facilitates language learning and subsequent learning activities [18]. Therefore, the words introduced at the beginning of every lesson are accompanied by their corresponding translation in Thai.

Following the vocabulary part is reading, which presents the historical accounts, related to the local culture of the temple next to the school. Because of the students' limited exposure to English, as is the case for English language teaching in Thailand in general, and lack of familiarity with other cultures yet, reading materials related to local contexts seem to be most beneficial. According to [21]-[24], the chance to read something related to their local community is likely to interest language learners more because it is related to their existing background knowledge or schema. Therefore, activating a schema is a crucial variable for reading comprehension. In this project, with the historical temple in full view near their school, the students are able to activate their temple-related schema while trying to understand what the reading text in English is about.

Another factor taken into consideration while devising instructional materials is the young age of the students. Lengthy reading materials might not be practical and appropriate for this school age. Therefore, in this study, each reading part consists of four to six sentences constructively based on the vocabulary presented in the first part of each lesson. Proper names of the temple and the Buddha image in English are accompanied by their equivalents in Thai in parentheses.

In summary, the control of the topic related to the students' schema, the length of the materials, and the L1 translation of the words were taken into consideration during the process of materials creation. The content of Lesson One is presented in Appendix B. All of the instructional materials were presented in colorful PowerPoint slides, with animations to make them attractive to young learners (not shown). A hard copy of the lessons was distributed to the students on the day of the class.

\section{E. University Student Volunteers and Classroom Management}

To ensure that the integrated instruction was smoothly conducted and to give university students an opportunity to serve the community using the knowledge gained from their course, four university students with English as their major or minor were recruited to assist with this project. The only requirement for the student volunteers was their availability on Fridays in December, 2013 (the days of the instruction). The accompaniment of four undergraduate student assistants at the school serves multiple purposes. First, these young learners at the Wat Khok Kham School, as reported by a school teacher, are different in their academic abilities. Some were much slower than the others in learning. To make sure that no student was left behind, individual attention from the four assistants became necessary. Second, these assistants were to provide support to the researcher in terms of marking tests, recording scores, monitoring individual students' pronunciation, and answering questions. The class time was from 9 to 11, with a 15-minute break in the middle. Fig. 3 depicts one of the roles of university students in this project.

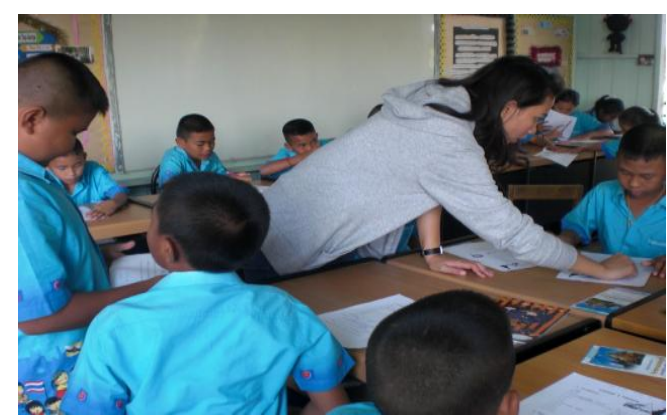

Fig. 3. University student volunteer and school students.

\section{F. Pre-Test Administration}

The pre-test written in Thai was administered in the first class meeting of the instruction. The purpose of the pre-test was to determine how much the students knew about the monastery adjacent to their school prior to instruction. It took the students about 15 minutes to complete the test. Upon completion of the pre-test, a pamphlet of the temple in Thai was distributed to the students. The pre-test was marked and recorded by the student assistants. One point was awarded for a correct answer, yielding a total of 15 points; no penalties were given for spelling mistakes.

\section{G. Lesson Delivery}

All activities of the lessons took place in the computer room of the school. In each lesson, with the help from the university student volunteers, the PowerPoint slides corresponding to the lesson were projected onto the screen, and the one page handouts of the lesson were distributed. The lessons were conducted by the researcher. For vocabulary, the researcher read aloud individual words to the students, with an emphasis on pronunciation because the meaning in Thai is already provided in the handout. Language games and activities were conducted individually or collectively to maximize the understanding and memorization of the words on the vocabulary list. The school students were split into four groups; each group with one student volunteer acting as a facilitator when a student had difficulty with certain words of the lesson. In the reading part, individual sentences containing the focused words were presented and practiced, to ensure they could understand the sentences. Similarly, language games and activities related to the reading part were conducted both individually and collectively in smaller groups to reinforce what was taught.

Towards the end of each class, the students were assigned to study the words they learned and get ready for the dictation task in the following class meeting. It should be noted here that the lessons offered by the researcher were only supplementary in nature. These students were to engage in their routine and regular academic classes and activities, including doing homework for other subjects. Therefore, the task of dictation played a minimal role in this integrated instruction. That is, it was used as a device to monitor their 
engagement, not to measure their spelling ability. Moreover, dictation in this study was used as a reinforcement of the pronunciation of the words learned in class. In this first class meeting, the students were told that they were expected to individually perform a role of a young tour guide in English in their last class meeting, showing a visitor the temple near the school.

In a subsequent class, the researcher reiterated the words and sentences for revision purposes. Then, the dictation task was administered to the class. The student assistants helped mark the dictation; one point was awarded to a correctly spelled word. The scores were recorded, but not included in the analysis. Not all of the students attended every class of the project for various reasons. Their attendance was thus indirectly recorded through the task of dictation. The students who missed a class were encouraged to ask their school teachers for help if they encountered problems understanding the handouts. Only the students who, at least, attended the first and the last classes, in which the pre-test and the post-test were administered, were considered participants of this study.

\section{H. Post-Test Administration}

In the last class meeting of the instruction, the revision of the three lessons was conducted by the researcher, followed by the post-test. Based on the same criteria of marking the pre-test, the post-test was marked and recorded by the student assistants. Again, the purpose of the post-test was to observe the students' possible knowledge gain after they had been exposed to the integrated instruction.

\section{Tour Guide Simulation}

After the post-test in the computer room in the last class meeting, the school students, the student volunteers, and the researcher proceeded to the nearby monastery precinct (Fig. 4). In this tour guide simulation activity, the students were instructed to pretend to be young tour guides, giving the description of the temple to foreign visitors. This activity was meant to compel the students to put their knowledge about culture and English into practice. Therefore, to accomplish this task, the students needed to demonstrate their cultural knowledge in English.

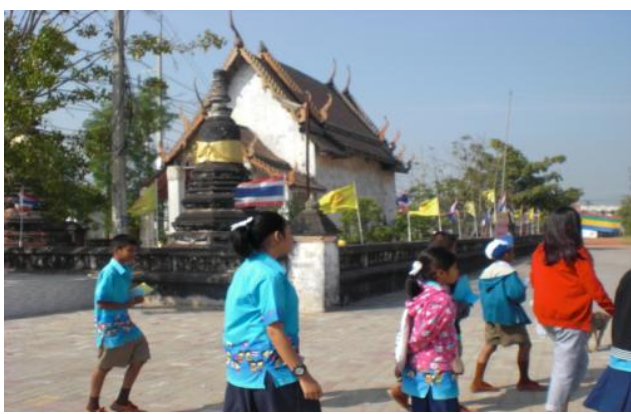

Fig. 4. Students proceeding to the nearby temple.

Due to time constraints of the school lunchtime at 11.30 and the large number of students, the school students were split into four smaller groups to ensure that this activity would be completed in time. Each group was supervised by one student volunteer. This tour guide simulation activity was administered individually, and each school students was required to produce about ten sentences in their description of the temple. No particular order was assigned, allowing them to execute the task when they thought they were ready. The handouts were allowed for preparation, but not allowed while engaging in the tour guide simulation task to avoid reading of the handouts.

The goal of this activity was to assess whether these students could put their integrated knowledge of local culture and English into practical use, and to give them a hands-on experience in being a young tour guide. Consequently, their performance was globally assessed, encouraging them to integrate the vocabulary knowledge and English skills learned in class. Fig. 5 shows a group of boy students sitting in front of the abbot, and Fig. 6 girl students at the side of the abbot, getting ready for the tour guide simulation task. Notably, no numerical scores were assigned for this activity. To evaluate their performance of this task, only 'satisfactory' and 'unsatisfactory' were awarded. Pronunciation deviation and grammatical mistakes were tolerable, as far as they could make themselves understood.

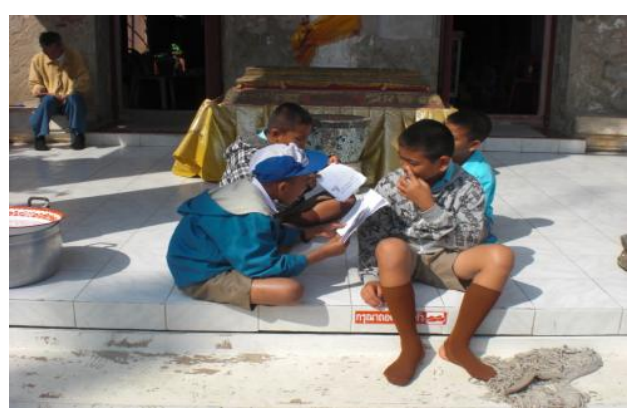

Fig. 5. Boy students getting ready for the tour guide simulation task

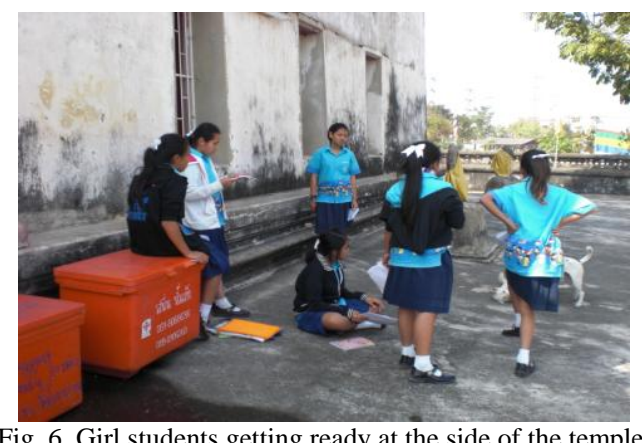

Fig. 6. Girl students getting ready at the side of the temple.

\section{J. Mini-Questionnaire Administration}

Finally, to estimate the students' attitude towards the integrated instruction, a brief questionnaire was administered upon completion of the tour guide simulation activity. Specifically, the school students were requested to answer two open-ended questions about the knowledge gained and their attitude towards the integrated instruction.

\section{RESUlts}

As shown in the school roster, this Grade 4 class originally consisted of 38 students. However, not all students attended the class regularly. Therefore, the final pool of the participants of this study includes those who at least participated in the pre-test and post-test. As a result, only 30 students were considered the ultimate participants of this research.

The results of this study came from multiple sources. First, 
the analysis of the pre-test conducted in the first class meeting revealed that out of the total score of 10 points, the minimum score of the entire class was 0 , and the maximum was 7 . The mean score of 3.03 clearly suggests that the school students, at the beginning of the project, generally possessed minimal knowledge of their local culture - the monastery by their school.

In the last class meeting of the instruction, the post-test was administered to observe the students' possible knowledge gain after they had been exposed to the integrated instruction. The pre/post-test scores were analyzed using descriptive statistics.

The analysis, as displayed in Table I, shows that the minimum score of the entire class was 5 , and the maximum was 10 . The average score of the entire class was 7.97 ; the average gain score was 5.23. In scrutiny, as shown in Table 1, every student performed better on the post-test, indicating their knowledge gain about the local culture of the historical temple.

\begin{tabular}{|c|c|c|c|}
\hline $\begin{array}{c}\text { Student } \\
\text { No. }\end{array}$ & $\begin{array}{l}\text { Pre-test } \\
\text { Score }\end{array}$ & $\begin{array}{c}\text { Post-test } \\
\text { Score }\end{array}$ & $\begin{array}{l}\text { Gain } \\
\text { Score }\end{array}$ \\
\hline 1 & 4 & 9 & +5 \\
\hline 2 & 2 & 7 & +5 \\
\hline 3 & 0 & 7 & +7 \\
\hline 4 & 1 & 7 & +6 \\
\hline 5 & 1 & 8 & +7 \\
\hline 6 & 2 & 8 & +6 \\
\hline 7 & 4 & 9 & +5 \\
\hline 8 & 3 & 10 & +7 \\
\hline 9 & 4 & 9 & +5 \\
\hline 10 & 6 & 9 & +3 \\
\hline 11 & 5 & 9 & +4 \\
\hline 12 & 7 & 9 & +2 \\
\hline 13 & 3 & 9 & +6 \\
\hline 14 & 3 & 8 & +5 \\
\hline 15 & 2 & 9 & +7 \\
\hline 16 & 7 & 10 & +3 \\
\hline 17 & 3 & 8 & +5 \\
\hline 18 & 3 & 8 & +5 \\
\hline 19 & 0 & 7 & +7 \\
\hline 20 & 2 & 8 & +6 \\
\hline 21 & 3 & 8 & +5 \\
\hline 22 & 2 & 7 & +5 \\
\hline 23 & 1 & 6 & +5 \\
\hline 24 & 3 & 7 & +4 \\
\hline 25 & 1 & 7 & +6 \\
\hline 26 & 3 & 8 & +5 \\
\hline 27 & 2 & 7 & +5 \\
\hline 28 & 0 & 8 & +8 \\
\hline 29 & 2 & 6 & +4 \\
\hline 30 & 3 & 7 & +4 \\
\hline Average & 3.03 & 7.97 & 5.23 \\
\hline
\end{tabular}

The comparison of mean scores pertaining to pre/post-tests was performed by a paired t-test. Significant increase in mean scores at $p .<0.01(t=17.22, p=0.000)$ indicates a significant increase of cultural knowledge. This finding highlights the positive impact, and the success, of the integrated instruction in developing the students' local culture awareness.

As for the task of tour guide simulation, some students were nervous of speaking English. Some of them took more time than others. However, every student satisfactorily completed the task, giving descriptions of the temple in English. The locals who happened to be at the temple at that time were impressed with these young tour guides although they did not seem to know what was going on.

Finally, the students' responses to the two questions on the mini-questionnaire were very positive. That is, when asked about the knowledge gained, all of the students congruently expressed that they had received a substantial body of knowledge from the instruction. Similarly, when asked about their attitude towards the integrated instruction, all of them expressed their keen interest in having the teaching team back at the school on a regular basis and for a longer period of time. One student explicitly stated that even though English was not easy for him, the student volunteers were indeed helpful, making him feel confident that he could speak English. In conclusion, the integrated instruction delivered over a five-week period proved to be successful, empowering the learners with motivation and positive attitudes towards the English language.

\section{DISCUSSION}

This research study was based on the premise that, upon transition of the country integration into AEC in the coming year and the attained status of English as a working language for the ASEAN region, Thai learners of English need to be better equipped with the English language. This paper focuses on enhancing young Thai learners' local culture awareness and English, a crucial foundation for subsequent development. The ideal setting of a school near a well-respected temple contributes to the formation of this project that integrates local culture into English lessons.

In this study, the integrated instruction of local culture and English was devised and implemented at an elementary school. A class of 30 Grade 4 students participated in this five-week project. Major instruments employed in this study include the pre/post-test to assess the students' local culture awareness before and after their exposure to the integrated instruction and teaching materials derived from the historical accounts of the temple. The significant gain scores towards the end of the instruction demonstrate that the instruction was successful in developing the students' cultural knowledge. To assess their use of English in performing a simulated task, all of the students were able to successfully execute the task in English. Finally, a mini-questionnaire eliciting the students' attitude towards the integrated instruction and related activities revealed that they found the instruction motivating, inspiring, and self-rewarding. As voiced out by all 30 students, if possible, they would like to participate in this type of instruction again in the future.

This study bears a number of pedagogical implications. First, an English class can be successful, making good use of students' background knowledge. As shown, the students in this study could triumphantly execute the task that might be considered daunting and intimidating for some people. However, because they were equipped with adequate background knowledge of the temple that matched the school context, the chance for failure was meager. To elaborate, the task that matched their schema became manageable. In the tour guide simulation task, the students were familiar with the local contexts and the settings, including the monastery site, the temple, and the sacred items. This familiarity provides 
them with a sense of security, guaranteeing their better chance of success [19]. At this juncture, the interplay between local culture and the English language has proved to be mutually beneficial. Teachers are in fact only facilitators, creating a venue for students to put their knowledge into practice.

Second, the findings of this study demonstrate that the integration of local culture and global English are potentially beneficial. However, as [20] cautioned, the integration should be incorporated into the curriculum to avoid unpleasant impacts of being haphazard, spasmodic, and unrewarding. Therefore, a lot of preparation and planning is required, including adequate scaffolding support provision and language task creation. As illustrated by this study, tour guide simulation was selected to represent one of the ways to elicit the authentic use of English that the students are likely to encounter in their real life.

Third, this study implicates the difference in value of instructional materials. Commercial textbooks seem to be of limited values in these contexts when learners' background knowledge or schema and identity are compromised. Therefore, in agreement with [21]-[24], who emphasize that the creation of in house instructional materials is especially crucial for young learners, allowing their background and identity to be fostered, encouraging learners' endeavors and striving to know more about others through the English language.

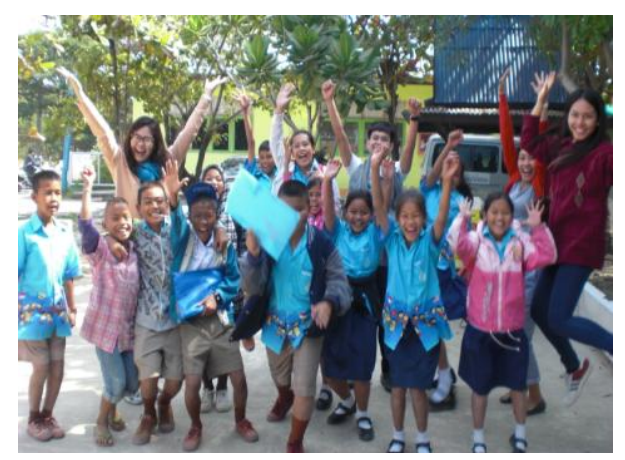

Fig. 7. Triumphant smiles at the end of the simulation task.

\section{CONCLUSION}

In conclusion, this study demonstrates how integrated instruction can be powerful, enhancing the students' awareness of the local culture and empowering the students as well as teachers to make full use of the students' existing background information in developing English competence. Also this kind of instruction is appropriate for this globalized era in which although global English knowledge becomes essential, local knowledge is not less important, significantly contributing to the formation of learners' identity. No words can conclude the success of this project better than Fig. 7.

\section{APPENDIX}

\section{A. Pre/Post-Test (10 Points)}

1) The School of Wat Khok Kham is near a temple named

2) This temple was built in the reign of King .................... .
3) This temple is about years old.

4) One of the sacred item or construction that you know is ....

5) The west of this temple is

6) Another name for Phra Phutthasihing is ...................

7) The person who built Phra Phutthasihing is ....................

8) One of the descriptions of Phra Phutthasihing is ................

9) Phan Thai Norasing is a ....... in the reign of King ............

\section{B. Lesson One}

\section{1) Part one: Vocabulary}

1) temple

2) the Khok Kham Temple

3) history

4) old

5) built

6) Ayutthaya period

7) Buddha

8) statue

9) province

10) respect

\section{2) Part two: Reading}

1) The temple was built in the Ayutthaya period.

2) This temple is more than 300 years old.

3) This temple has the Buddha statue Phra Phutthasihing or Luang Phor Samrit.

4) Everyone in this province respects this Buddha statue.

\section{ACKNOWLEDGMENT}

This research project would not have been possible without the kind cooperation from the following individuals. First, my gratitude goes to the headmaster of Wat Khok Kham School and his teaching staff who accommodated my teaching schedule on Fridays in December, 2013. Next, the success of this project was attributed to assistance from four fourth year students from the Faculty of Arts, Silpakorn University who willingly spent their Fridays with young learners, sharing with them their English knowledge. Finally, my sincere appreciation goes to thirty Grade 4 students who welcomed my lessons with their sparkling eyes, enthusiasm, and curiosity throughout the project.

\section{REFERENCES}

[1] R. Kirkpatrick, "English education in Thailand: 2012," Asian EFL Journal, vol. 61, pp. 24-40, 2012.

[2] K. Prapphal, "English proficiency of Thai learners and directions of English teaching and learning in Thailand," The English Teacher, vol. 6, no. 2, pp. 144-152, 2003.

[3] National Statistical Office. (August, 2012). The Reading of Population Survey 2011. [Online]. Available: http://web.nso.go.th/en/pub/index_more.htm

[4] Assumption College Thonburi. (June 2009). The Basic Education Core Curriculum B.E. 2551 (A.D. 2008). [Online]. Available: http://www.act.ac.th/document/1741.pdf

[5] B. Laufer, "What's in a word that makes it hard or easy: Some intralexical factors that affect the learning of words," in Vocabulary: Description, Acquisition and Pedagogy, N. Schmitt and M. McCarthy, Eds., United Kingdom: Cambridge University Press, 1997, pp. $140-155$. 
[6] B. Laufer and J. Hulstijn, "Incidental vocabulary acquisition in a second language: The construct of task-induced involvement," Applied Linguistics, vol. 22, no. 1, pp. 1-26, 2001.

[7] C. B. Zimmerman, "Historical trends in second language vocabulary instruction," in Second Language Vocabulary Acquisition, J. Coady and T. Huckin, Eds., Cambridge: Cambridge University Press, 1998, pp. 5-19.

[8] T. Cobb, "Computing the vocabulary demands of L2 reading," Language Learning and Technology, vol. 11, no. 3, pp. 38-63, 2007.

[9] P. Nation, "Teaching vocabulary," Asian EFL Journal, vol. 7, no. 3, pp. 47-54, 2005

[10] W. Grabe, Reading in a Second Language: Moving from Theory to Practice, New York, NY: Cambridge University Press, 2009.

[11] W. Grabe and F. Stoller, "Reading and vocabulary development in a second language: A case study," in Second Language Vocabulary Acquisition, J. Coady and T. Huckin, Eds., Cambridge: Cambridge University Press, 1998, pp. 98-122.

[12] M. Adams, "Afterword: The science and politics of beginning reading practices," in Reading Development and the Teaching of Reading, J. Oakhill and R. Beard, Eds., Oxford: Blackwell, 1999, pp. 213-227.

[13] C. Perfetti, "Reading ability: Lexical quality to comprehension," Scientific Studies of Reading, vol. 11, pp. 357-283, 2007.

[14] C. Perfetti, N. Landi, and J. Oakhill, "The acquisition of reading comprehension skill," in The Science of Reading: A Handbook, M. J. Snowling and C. Hulme, Eds., Oxford: Blackwell, 2005, pp. 227-247.

[15] M. Calderon, Teaching Reading to English Language Learners, Grades 6-12, Thousand Oaks, CA: Corwin Press, 2007.

[16] S. Thornbury, How to Teach Vocabulary, Boston: Pearson Education, 2002.

[17] M. Lewis, Teaching Collocation: Further Developments in the Lexical Approach, London, UK: Language Teaching Publications, 2000.

[18] G. M. Jacob, P. Dufon, and C. H. Fong, "L1 and L2 vocabulary glosses in L2 reading passages: Their effectiveness for increasing comprehension and vocabulary knowledge," Journal of Research in Reading, vol. 17, pp. 19-28, 1994.
[19] H. Bishop, "The effects of typographic salience on the look up and comprehension of unknown formulaic sequences," in Formulaic Sequences, N. Schmitt, Ed., Amsterdam: John Benjamins, 2004, pp. 227-248.

[20] M. Yoshii, "L1 and L2 glosses: Their effects on incidental vocabulary learning," Language Learning and Technology, vol. 10, no. 3, pp. 85-101, 2006.

[21] M. Williams and R. L. Burden, Psychology for Language Teachers, Cambridge: Cambridge University Press, 1997.

[22] J. Macalister, "Implementing extensive reading into an EAP programme," ELT Journal, vol. 62, no. 3, pp. 248-256, 2008.

[23] V. Yu, "Extensive reading programs - How can they best benefit the teaching and learning of English," TESL Reporter, vol. 26, no. 1, pp. $1-9,1993$.

[24] R. R. Day and J. Bamford, Extensive Reading in the Second Language Classroom. Cambridge: Cambridge University Press, 1998.

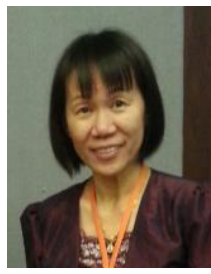

Budsaba Kanoksilapathm was born in Samut Sakhon, Thailand. She completed her bachelor's degree in English at Chulalongkorn University, Thailand (Second Class Honors). She also completed her master's degree in both linguistics and English as a foreign language (EFL) at Southern Illinois University at Carbondale (SIUC), Illinois and her doctoral degree in linguistics (concentration: applied linguistics) at Georgetown University, Washington DC, USA in 2003.

She is currently a professor at the English Department, Faculty of Arts, Silpakorn University, Nakhon Pathom, Thailand. Her most recent books are Pronunciation in Action and English Sociolinguistics at Work. Her research articles were published in international journals including English for Specific Purposes, The IEEE Transactions on Professional Communication, and 3L: The Southeast Asian Journal of English language Studies.

Dr. Budsaba Kanoksilapatham has served as a reviewer for a number of both national and international journals. 